\title{
LOOK OUT FOR SIGNS OF CHILD NEGLECT, DCPS WARNED
}

All members of the dental team should look out for signs of child abuse and neglect, paediatric specialists have warned.

Speaking at a study day on safeguarding children in dentistry at the Royal College of Surgeons, Jenny Harris, specialist in paediatric dentistry, Sheffield salaried primary dental care services, urged all members of the practice team to share their knowledge and concerns and to look out for danger signals such as missed appointments.

'Child maltreatment and dental caries occur side by side in deprived communities,' she said. Research showed more than $60 \%$ of dentists saw children with neglected teeth every day. But $40 \%$ had never made a referral to social services, or inquired whether a child was on the child protection register, she told the meeting.
Dr Harris, who will be speaking at the British Association of Dental Therapists conference in Liverpool this month (20-21 June) suggested that staff concerned about a child's dental neglect should adopt a three stage process: first raising issues with parents and monitoring progress, then checking the child protection register and liaising with other agencies, before, finally, making a referral to social services if the situation is deteriorating.
PRACTICE

\section{ACCREDITATION SCHEME LAUNCH}

Heart of Birmingham PCT plans to launch a practice accreditation scheme this year which will involve development plans for all team members.

Each practice will be offered a day's quality review, funded by the PCT, and accredited practices will be expected to display a 'patient's promise' and organise patient forums. Requirements for accreditation will include diagnosis and treatment plans, agreed with the patient, holistic history taking and health promotion advice.

Announcing the scheme, Ros Hamburger, consultant in dental public health for Heart of Birmingham PCT, said the scheme aimed to boost oral health promotion.

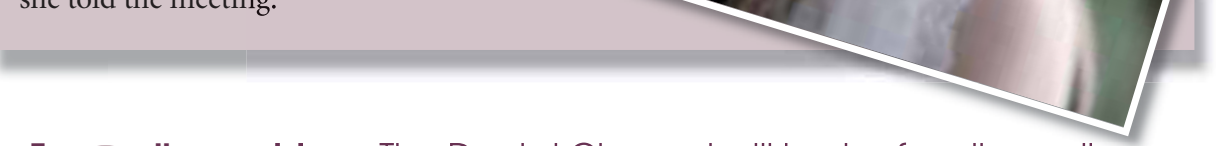

Free online webinar The Dental Channel will host a free live online webinar from 1pm-1.45pm on Thursday 3 July 2008. The new service will enable dental nurses to participate in lively and engaging CPD directly from their practice.

The formal programme will commence on 3 September 2008 and initially will provide 11 one hour lectures ( 11 hours' verifiable CPD) covering a wide range of topics. See www. dental-channel.co.uk.

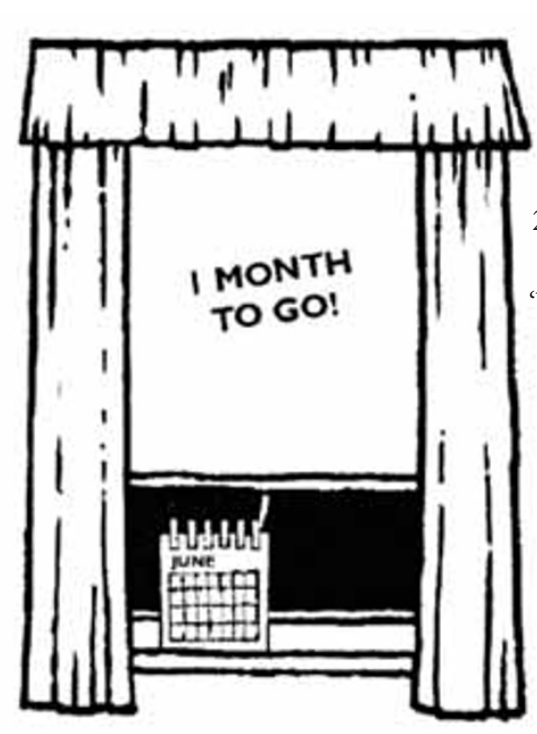

\section{REGISTRATION FIGURES}

More than 36,000 dental care professionals have registered with the GDC, according to the latest figures. Of the 36,706 DCPs who had registered by mid April, 27,660 were dental nurses and 3,641 were dental technicians. Edward Bannatyne, GDC director of operations, said 'We're really pleased so many dental technicians and dental nurses are now registered with us. But if you haven't applied yet, please don't leave it too late. This is especially true if you are counting on applying on the basis of your experience as 30 July is the absolute cut-off date. After that the only way on to the register will be with an up to date qualification.'

The GDC has also warned potential registrants working in a clinical environment that they must provide written proof of immunity to Hepatitis B and that testing could take several weeks to arrange.
Forensic dentist Judy Hinchliffe is one of the speakers at the scientific meeting of the British Association of Dental Therapists to be held in Liverpool this month (20-21 June). Dr Hinchliffe took part in the identification of victims of the tsunami in Thailand in 2004 and the aftermath of the bombings in Sharm el Sheikh, Egypt, in 2005, when more than 80 people were killed. She has been involved in several murder inquiries. She will be talking about child abuse and physical injuries to children, drawing on cases she has been involved in.

Other speakers include Jenny Harris, paediatric specialist for Sheffield salaried dental service, on safeguarding children in general dental practice, and 'celebrity' Manchester dentist Phil Wander. Founder member and chair of the British Homeopathic Dental Association, who has treated David Beckham and Eric Cantona, Dr Wander will talk about complementary and alternative therapies in dentistry.

Craig Barclay, consultant in restorative dentistry, will speak on the maintenance of dental implants. 